\title{
LA NARRATIVA BREVE EN LA MISCELÁNEA DEL SIGLO XVII ${ }^{1}$
}

\author{
JONATHAN BRADBURY \\ University of Exeter \\ j.bradbury@exeter.ac.uk
}

$\mathrm{D}$ esde el artículo seminal de Rallo Gruss (1984), la tradición de la miscelánea vernácula en la España del siglo Xvi se ha aclarado considerablemente, con valiosas aportaciones de estudiosos como Alcalá Galán (1996) y Malpartida Tirado (2007) entre otros. Se ha evidenciado una continuidad entre las misceláneas clásicas y humanistas y las españolas, y se ha descrito el desarrollo de éstas a lo largo del Quinientos. Entrado el siglo XVII, la situación se complica; no es difícil identificar puntos de contacto entre la Silva de varia lección (1540) de Mexía y obras como el Tesoro de diversa lección (1636) de Ambrosio de Salazar — aunque un librito de este tipo represente un claro declive del género-, y podemos postular además varias semejanzas conceptuales y formales entre las misceláneas del siglo xvi y obras como los Días de jardín de Cano y Urreta (1619), las Noches claras (1624) de Faria e Sousa, y hasta las Cartas filológicas (1634) de Cascales. El problema crucial consiste, no obstante, en intentar trazar una línea entre las misceláneas tradicionales, como la de Mexía y el Jardín de flores curiosas (1570) de Torquemada, cuya materia narrativa se limita a ejemplos, anécdotas y cuentos breves (Chevalier 1982; Yarbro-Bejarano 1991: 47-61), y los textos de contenido heterogéneo del siglo siguiente que presentan una alta tasa de literatura imaginativa.

Mi propósito en este estudio no es arriesgar una respuesta detallada a esta interrogación, sino que es mucho más modesto: ofrecer algunas observaciones sobre la presencia y la función de la narrativa corta en unas misceláneas de la primera parte del Seiscientos. Habrá que adoptar de todas formas una formulación heurística que permita identificar las misceláneas del XVII, y propongo que

1 Este trabajo se inscribe en el marco del Proyecto I+D+i del MINECO La novela corta del siglo XVII (y II) (FFI2013-41264-P). 
esta identificación se efectúe a través de una consideración de la medida en que una presunta miscelánea tardía preserve la función fundamental de las misceláneas tempranas: la colección y transmisión a lectores medios de hechos y datos normalmente fuera de su alcance, con un énfasis particular en materias eruditas. Según este acercamiento, no calificaríamos como misceláneas, por ejemplo, las dos obras de Tirso que contienen novelas. El uso explícito que hace fray Téllez del término «miscelánea» (Molina 1994: 9) en la dedicatoria del Aprovechar deleitando (1635) no representa una adscripción genérica, sino que se refiere a la hibridación de temas sacros y a la forma literaria de la novela corta, mientras que los Cigarrales de Toledo (1624), obra escogida por Laplana Gil como típica de la «miscelánea barroca» (Bondía 2000: xxxvi), sólo coquetean con la erudición. Tirso escribe que los protagonistas de los Cigarrales rivalizan con los autores emblemáticos de misceláneas clásicas, conduciendo «disputas tan curiosas como claras que pudieran dar envidia a las Noches áticas de Aulo Gelio y Días saturnales de Macrobio» (Molina 1996: 232), pero el autor no transcribe estos debates, dándole preferencia a contenidos literarios.

Pérez de Montalbán, por otro lado, otorga en el Para todos (1632) una presencia bien visible a los temas eruditos, que expone en forma de discursos académicos, y los aprobadores del libro, José de Valdivielso y Diego Niseno (Pérez de Montalbán 1999: 465-467), procuran integrar la obra en la misma tradición clásica y humanista que evocan Mexía (2003: 40), en los preliminares de la Silva, y Diego de Arce, en los de la Miscelánea de oraciones eclesiásticas (1606) (Bradbury 2010: 1068). No quiere decir que tal contenido docto no resulte frecuentemente trivial y pedantesco, pero percibimos entre las piezas teatrales, la poesía y las novelas cortas del Para todos la importancia capital de estos elementos informativos en la concepción del autor. Aceptar tal interpretación de una de las posibles evoluciones de la miscelánea en el siglo XVII nos ayuda a agrupar libros de apariencia barroca, lejos del desorden deliberado de las misceláneas primitivas, como el mismo Para todos, en cuyo aspecto formal Pérez de Montalbán (1999: 595) dice haber invertido una labor considerable («he gastado medio año en su disposición [...] [P] ara no errarle le he borrado infinitas veces»), con otros de estructura infinitamente más sencilla, como son las «conversaciones familiares» de El filósofo del aldea (1625) de Baltasar Mateo Velázquez, en las que se dan la mano también la erudición y la narrativa breve.

Sin embargo, dicha taxonomía resultaría estéril si no se investigara además la relación que conciben los autores de este tipo de misceláneas entre los materiales eruditos y ficcionales. Tales investigaciones serán particularmente fructíferas cuando analicemos las narraciones breves dentro de las misceláneas de las primeras décadas del siglo Xvir, ya que la preceptiva informal que se esboza por aquellos años hace hincapié en el carácter docto de la narrativa corta. Lope subraya, 
al inicio de Las fortunas de Diana, novela publicada en La Filomena (1621), la necesidad de que los novelistas sean «hombres científicos, o por lo menos grandes cortesanos, gente que halla en los desengaños notables sentencias y aforismos» (Vega 2011: 106; Schwartz 2000). Con ello se hace eco del portugués Rodrigues Lobo, quien había declarado la importancia en la novela corta, que él llama história, de las «sentenças com que se autorize» (Rodrigues Lobo 1945: 210), en su Côrte na aldeia e Noites de inverno (1619), obra que ocupa un espacio incierto entre manual literario (con ejemplos prácticos de la novela y el cuento), tratado de cortesanía, y miscelánea, y que se traduciría en castellano en 1622.

Consejos semejantes se encuentran en El pasajero (1617) de Suárez de Figueroa, libro significativo en esta conexión, visto que se trata de una miscelánea dialogada de rasgos costumbristas que consolida el aspecto anecdótico y local de las misceláneas de la última parte del siglo XVI, como la Varia historia manuscrita de Zapata, además de explorar la teoría y la práctica de literatura imaginativa. Consabido es que Suárez de Figueroa define la novela corta como una «composición ingeniosísima» que debe ser «mañosa y vestida de sentencias, documentos y todo lo demás que puede ministrar la prudente filosofía» (Suárez de Figueroa 1988: I, 179), pero no se ha llevado a cabo todavía un estudio de la ficción corta en la prosa de El pasajero que coteje las afirmaciones teóricas del autor con su práctica novelística. En realidad, las novelas cortas de esta miscelánea, del mismo modo que sus cuentos y cuentecillos, no presentan ninguna interacción sustancial con la erudición o los elementos informativos del volumen, constituyéndose principalmente en las autobiografías de tres de los cuatro interlocutores: Luis (I, 144161), el Maestro (I, 257-276) y el Doctor (II, 437-559). Lo que más destaca en cada caso son la presentación - frecuentemente satírica- de tipos sociales y los detalles picarescos, y la novela del Doctor sirve también de marco a otras dos vidas, de un ermitaño (II, 465-472) y un ventero (II, 480-509), la última de las cuales contiene una reescritura que españoliza parte de una novella del Decamerón (Arce Menéndez 1975). Aunque las novelas generan varios comentarios morales, generalmente expresados post factum por los interlocutores-oyentes, su función fundamental se reduce a aumentar la variedad - temática y, cada vez más en el XVII, formal — exigida por la miscelánea, estrategia a la cual alude el Maestro: «Si se pudiesen escribir los sucesos de muchas vidas, ¡qué silva de varia lección se hallaría en ellas!» (Suárez de Figueroa 1988: II, 510).

A pesar de las diferencias estructurales entre las dos misceláneas, ciertos elementos eruditos de El pasajero tendrían cabida en los discursos académicos del Para todos — sería el caso de las disquisiciones de Suárez de Figueroa (I, 287303) sobre la oratoria sagrada, plagiados del predicador italiano Panigarola (Cerdan 1987) — , pero entre la materia novelística de las obras apenas hay semejanzas. Aunque las novelas cortas que incluye Pérez de Montalbán (1999: 532-575; 
630-667; 757-800) en el cuerpo de su miscelánea también son tres (Al cabo de los años mil, El palacio encantado y El piadoso bandolero), la tercera de las cuales contiene además la vida de un ermitaño contada por él mismo, estas ficciones en prosa tratan en clave ortodoxa cuestiones serias - y eternas - de amor, honor y relaciones sociales. La acción de la segunda novela se desarrolla fuera de la Península, en Grecia, durante un período histórico indeterminado, mientras que la primera y la tercera se ambientan en España y sus posesiones italianas, pero ni siquiera en estos dos casos advertimos de manera sostenida los contornos definidos de la sociedad española aurisecular. Tal descripción no se debe interpretar, sin embargo, como un juicio negativo sobre el valor artístico de las novelas; el traductor inglés de Pérez de Montalbán en 1709, Edward Ward, reconoció las calidades literarias de la primera y la tercera, traduciendo solo estas y el marco prosístico de la miscelánea, y descartando el resto del contenido del Para todos, y el editor Alfay en 1659 escogió Al cabo de los años mil para encabezar el Bureo de las musas, refundición de El buen humor de las musas (1630) de Polo de Medina.

En el prólogo del Para todos, Pérez de Montalbán (1999: 469) contrasta el proyecto actual con su profesión habitual de dramaturgo, destacando los inconvenientes en el ámbito del teatro de querer «guisar un plato que contente a todo un pueblo entero, siendo sus gustos tantos como diferentes»; su apropiación de una técnica miscelánea le ha permitido confeccionar un «aparato de varias materias» con el cual superar este problema y proveer algo para cualquier lector (470). Quevedo (1993: 471) juzgó tal pretensión «vulgar y bazofia» y tachó la multiplicidad de contenidos de indecorosa; además, en una carta de Jerónimo de la Vera (Del Piero 1961: 41) que formó parte de la misma polémica, se propone una crítica específica de la mezcla de hechos objetivos con ficciones, o de «verdades católicas con fábulas y novelas»; Vera sugiere que la incorporación de tales elementos ficcionales se debe a un deseo de abultar el libro y a una tentativa más siniestra de burlar la prohibición de la Junta de Reformación si se trataba de «imprimir libros de comedias, novelas ni otras deste género», en vigor entre 1625 y 1634 (Cayuela 1996: 39). Las dos acusaciones son creíbles, aunque hagan caso omiso de la prevalencia de la literatura imaginativa en las misceláneas del siglo xviI; si queremos conceder a Pérez de Montalbán el beneficio de la duda, habrá que establecer el papel que desempeñan las novelas cortas a la hora de cumplir con la promesa hecha en el prólogo de presentar «juntamente utilidad y gusto, erudición y divertimiento, doctrina y desahogo» para toda clase de gente (Pérez de Montalbán 1999: 470). En efecto, una función bivalente se atribuye a las dos primeras novelas durante el reparto de las responsabilidades que estructurarán esta «cortesana academia»: se describen respectivamente como «ejemplar y gustos[a]» y «útil y entretenida», mientras que en el tercer caso a Celio sólo se le ordena «divertir el auditorio con una historia imaginada» (491). No obstante, los comentarios pronunciados por 
los personajes al concluirse las secciones narrativas enfatizan sobre todo la función lúdica de las novelas; los participantes alaban la «pureza del lenguaje» (575) y la «gustosa y entretenida novela» (667); y después de El piadoso bandolero, se afirma que la «materia tan dificultosa» del discurso académico precedente ha sido «sazonada de los artes» (800). Esto no implica ninguna relación efectiva entre los dos apartados; más bien, representa una analogía textual a la dispensa concedida a las damas al inicio de la semana, cuando se les da permiso para «trocar la academia por el campo, los discursos por las flores» (491) si la exposición de temas eruditos — el fruto de la miscelánea - por parte de los hombres les parece enfadosa.

Al demostrar sus habilidades para contar ficciones con gracia y soltura ante un grupo de tertulianos, los tres caballeros que novelan cumplen un requisito imprescindible del hombre bien educado, calidad tratada por autores del siglo precedente como Castiglione y Della Casa (y sus refundadores españoles, Boscán y Gracián Dantisco), y también por Rodrigues Lobo pocos años antes en la Côrte na aldeia. Lo que no consiguen —o no intentan conseguir - los caballeros es la incorporación consistente a las narraciones del elemento erudito reclamado por Lope y Suárez de Figueroa. Se encuentra una sola excepción, en la forma de un breve discurso sobre los atributos de príncipes en El palacio encantado (Pérez de Montalbán 1999: 658-662), una «docta oración» que, según la hipótesis de Dixon (1964: 43), podría ser una interpolación de contenido que Pérez de Montalbán no lograba integrar en otra parte discursiva del libro, y que ilustra en medida muy limitada la maleabilidad y cabida de la novela corta áurea, calidad señalada por Albert (2013: 277-279). Pero, por lo demás, Pérez de Montalbán sigue la pauta establecida en sus Sucesos y prodigios de amor (1624), conjunto en el cual las novelas, destinadas a un público general, asumen la parte más anodina y menos sustancial de la erudición del volumen (Sendín Vinagre 1998: 198-200); si en los Sucesos y prodigios son las dedicatorias individuales a las novelas donde Pérez de Montalbán trata de dar muestras convincentes de su erudición, en el Para todos lleva a cabo el mismo proceso, aunque en proporciones masivas, mediante los discursos académicos. La separación entre los contenidos eruditos y narrativos no es tan cruda como la que detectamos en los Discursos morales (1617) de Cortés de Tolosa, una obra similarmente abigarrada en la cual las cuatro novelas cortas ocupan una posición aislada, confinadas en el tercer libro del tomo, pero la inserción de las novelas a intervalos regulares en el cuerpo del Para todos (al final del segundo, del cuarto, y del sexto día) sólo garantiza una complementariedad superficial y no favorece una relación de dependencia o interacción seria entre los propósitos eruditos de la miscelánea y sus ficciones.

Ejemplo muy distinto de una combinación de erudición y narrativa corta es $E l$ filósofo de aldea, cuyo autor firma como «el alférez don Baltasar Mateo Velázquez». Esta identidad se considera seudónima, quizás, de Fray Alonso Remón, y 
se ha postulado con unas pruebas convincentes una autoría común para El filósofo y la Guía y avisos de forasteros (1620), libro que alberga materia novelística y contenido práctico sobre la vida en la capital, salido de la pluma de un tal Antonio de Liñán y Verdugo, otro probable seudónimo (González Ramírez 2011: 33-42; Fernández Nieto 2013). Aunque El filósofo, texto dialógico con un marco muy básico, es de extensión modesta (el cuerpo de la primera edición consta de 96 folios en octavo), sus discursos eruditos son variados, convirtiendo el libro en una verdadera miscelánea aunque algunos estudiosos modernos lo hayan considerado una colección de novelas cortas (Colón Calderón 2001: 142). Tal confusión es comprensible y está presente ya en las poesías preliminares del volumen; el soneto compuesto por la «sobrina» del autor destaca el contenido ficcional de El filósofo, calificando la técnica literaria de su tío como «esmalta[r] la fabulosa historia / con el fruto moral» (Velázquez 1906: 154), aunque el «sobrino» de Velázquez nos da una visión más neutra, encomiando el «Sabroso conversar, rato escogido / y provechoso entretener de aldea» (155).

Otra posible interpretación de la obra como un conjunto de narraciones cortas encontramos en la tercera edición, casi seguro póstuma y publicada por Diego Dormer (menor) en Zaragoza. La edición, de una calidad pésima, no lleva año de impresión, y, aunque la crítica ha propuesto una fecha alrededor de 1650 (González Ramírez 2007: 46), podemos fecharla con bastante certeza hacia 1670, como demostraré en un estudio futuro. De todas formas lo que importa en esta edición tardía es la adición — realizada con una torpeza decepcionante - al final de la última conversación de El filósofo de la novela de El duende de Zaragoza, sacada de La quinta de Laura (1649) de Castillo Solórzano. No sabemos a quién se debe tal decisión —al impresor, a Juan Fernández, el librero madrileño que costeó, al menos en parte, la edición, o a otra persona-, por motivos comerciales, claro está, pero lo cierto es que delata una visión del libro que lo considera principalmente un amontonamiento de breves prosas ficcionales. Además, en uno de los ejemplares de esta edición de Zaragoza que posee la Biblioteca Nacional de España (2/5664) aparece una «Tabla de los sucesos de este libro», la cual casi exclusivamente dirige al lector hacia la materia ficcional de la miscelánea. Las novelas cortas y otro tipo de narrativa breve que forman una gran parte de El filósofo original, esbozadas en sus líneas generales por Fernández (1983: 187-190), no son tan elaboradas como las del Para todos, ni siquiera como la de El duende de Zaragoza, pero tampoco son de escasa calidad literaria, y tres de los cuatro «casos» que refiere el protagonista titular sobre el trillado tema de la fortuna (Velázquez 1906: 243290) gozan de una vida suplementaria en el siglo xvIII, apareciendo en la edición de 1709 de los Varios prodigios de amor, antología del librero Isidro de Robles publicada por primera vez en 1666. 
Todos los preliminares legales de El filósofo se firman en 1624, lo que excluye la posibilidad de que la miscelánea sirviera como pretexto para burlar la prohibición de libros de novelas impuesta por la Junta, y la médula del tomito son los materiales eruditos. Tal enfoque es evidente ya en el título, y se reafirma en la introducción a las conversaciones; se le describe a Prudencio, el filósofo epónimo, como un autodidacta que «lo más del tiempo gastaba en leer algunos libros de romance, así doctrinales como historiales» (Velázquez 1906: 163) y «se entremet[ía] a disputar materias, o familiares o políticas, y a referir casos y sucesos de que tenía noticia, citando los libros en romance en que había hecho y hacía tan ordinario y continuo estudio a la mañana y noche» (165). El énfasis sobre las fuentes vernáculas de su erudición recuerda al autorretrato que firma Melchor de Santa Cruz en sus Cien tratados (1576), y se repite a lo largo de El filósofo; se nos da a entender que la mayoría de las citas clásicas y humanistas que pueblan la conversación del filósofo proceden de traducciones u otros textos intermedios en castellano, lo cual distancia esta miscelánea de tantas otras de la tradición que remiten — a menudo falsamente- a fuentes directas latinas. Hay también un fuerte componente nacional en los saberes del volumen; así, en la tercera conversación, sobre asuntos pertenecientes a la política y al buen gobierno, los interlocutores se maravillan de Prudencio y «su capacidad suficiente para cualquiera género de materias» (223), y el filósofo abre el discurso con un elenco de los textos que aprovechará (224-225): las obras escritas en castellano son diez, todas de los siglos XVI y xviI, y las traducidas son cuatro, una de las cuales es el Llibre de les dones del catalán Francesc Eiximenis.

En el libro de Velázquez el debate erudito se concibe como un pasatiempo sano, como en la Casa del placer honesto (1620) de Salas Barbadillo, aunque en la Casa, como en los Cigarrales, sólo se alude a la erudición, sin que el autor presente ejemplos de discusiones intelectuales. El grupo que invita al sabio aldeano a participar en sus tertulias — compuesto por «algunos caballeros mozos y algunas personas graduadas en diferentes facultades» (Velázquez 1906: 167), combinación de cortesanía y erudición que cristaliza en las personas de Juan, el caballero principal, y del Doctor, «arguyentes y contrapuntantes» (175) del filósofo- no toma la decisión sólo para satisfacer su curiosidad, sino para evitar el «mal fin» que tienen de ordinario sus tertulias, «como parar siempre en jugar, quitándose las haciendas y resultando de ahí otros mayores inconvenientes» (166). En estas primeras páginas del libro no se encuentran alusiones a los elementos novelísticos que ocuparán una posición importante en la maquinaria de la obra, y hay incluso una advertencia sobre el efecto negativo que pueden ejercitar las ficciones frívolas sobre los niños, cuando el filósofo aconseja al padre de familia que «Cuentos y consejas a tus hijos e hijas no se las leas» (176). 
La primera narración —-muy corta- es la «Relación del suceso trágico de Polimo y Sigeldo, su hijo» (178-183); la cuenta el Doctor —aunque será el filósofo quien se encargue de la mayoría de los contenidos narrativos del volumen-, y sirve para ejemplificar e ilustrar la materia doctrinal que se acaba de presentar sobre cómo se han de comportar los padres. Ésta será la función primaria de la narrativa en esta miscelánea, tal y como las novelas y relatos de la Guía y avisos sirven para reforzar las enseñanzas sobre la corte (Rallo Gruss 2013); percibimos la misma modalidad aún más claramente cuando Juan pide al filósofo un «ejemplo [...] acerca del criar las madres sus hijas a sus pechos y no darlas a amas ajenas» (Velázquez 1906: 183). Prudencio accede a la petición, pero insiste en referir en primer lugar «lo que he leído en algunos autores acerca de lo que importa que las niñas tiernas mamen la leche de las mismas que las parieron», desplegando una erudición sintética y nunca recóndita que comprende a Aristóteles, Cicerón, Macrobio y fray Luis, entre otras autoridades (184-188). Pospone así la «Relación del caso peregrino y extraordinario de las dos Isabelas» (190-197), estableciendo una manifiesta jerarquía entre los dos tipos de contenidos, dentro de la cual desempeña la ficción un papel subordinado pero a la vez fundamental.

La naturaleza de la materia narrativa de El filósofo varía mucho: el Doctor afirma haber leído el suceso de Polimo «en un libro antiguo» (183), el filósofo presenta la novelita de las Isabelas como un caso verdadero, si bien a él se la ha relatado «cierta persona que, así por ser quien era y en el oficio que estaba puesta, se podía dar crédito» (189), y los dos bloques narrativos que concluyen la segunda conversación, referidos por el filósofo y Juan respectivamente, provienen de su experiencia personal y tienen por tanto un fuerte matiz local (202-223). Esto no quiere decir que no haya narrativas que se presenten como ficcionales, implícitamente, como la narración de «la lastimosa pérdida del reino del rey Ebandro» (230-237), después de la cual los contertulios alaban el «buen lenguaje y estilo del aldeano filosofo» (238), o explícitamente, como sucede con las cuatro novelitas que se agrupan bajo el título Los casos acaso. El filósofo las describe como «unos sucesos que parte tienen de ejemplo y parte de entretenimiento» (243); es decir, son ejemplares tanto porque ejemplifican los argumentos discursivos sobre el tema de la fortuna como porque evalúan comportamientos negativos y positivos en situaciones difíciles, y tales aspectos morales no excluyen la función lúdica de estas novelas cortas. Al final del cuarto «caso», se subraya la síntesis de las dos características, clave de la eutrapelia, cuando los protagonistas elogian el «agudo ingenio» $\mathrm{y}$ «buen celo» de Prudencio (291). Aún más significativo resulta el hecho de que el mismo filósofo es el autor de estas narraciones intradiegéticas, las cuales se presentan explícitamente como un «librito» cohesivo de su propia autoría (242-243); por tanto, además de ser hombre erudito, receptor y ahora transmisor de lecciones misceláneas, es escritor de narrativa corta, encarnando así de forma modesta el ideal del novelista 
polifacético propuesto por Lope, y Suárez de Figueroa, de ahí que los oyentes acojan con deleite el discurso de Prudencio, «ora fuese histórico, ora fabuloso» (291).

Otro texto que ha dividido la crítica acerca de su estatuto genérico es las Noches de invierno (1609) de Antonio de Eslava; para Ripoll (1991: 24) se trata de una «miscelánea dialogada», mientras que otros estudiosos lo consideran una colección de novelas cortas (Mata Induráin 2003). Es verdad que el texto de Eslava proporciona en abundancia las dos mismas cualidades, erudición y novelística, que hemos señalado en la miscelánea que publicaría Velázquez dieciséis años después, y Barella Vigal (Eslava 1986: 18-19) ha notado la doble connotación del título del libro, recuerdo por una parte de las novelle de las Piacevoli notti (15501555) de Giovanni Straparola — paralelo confirmado además por la ambientación veneciana del texto de Eslava, tan distinta de la torrelagunense de El filósofo- y de la tradición indígena española de contar historias para aliviar el frío invernal; y por otra parte evocación de las elucubraciones del autor de la miscelánea arquetípica de la Antigüedad: Aulo Gelio y sus Noctes atticae («hibernarum vigiliarum», Praefatio 10), un eco apreciado por el hermano del autor en un soneto preliminar que termina por declarar que Antonio «imita a otro Gelio en sus Catálogos» (Eslava 1986: 60).

En efecto, en las Noches de invierno tenemos un texto en el que la erudición y la narrativa desempeñan una relación de codependencia, pero el libro de Eslava presenta una imagen perfectamente especular de El filósofo del aldea; se invierte la naturaleza del vínculo entre los dos componentes, otorgándose la prioridad lógica a las novelas. Al inicio de la obra, mientras los interlocutores proyectan las tertulias que formarán el cuerpo del texto, descritas a lo largo de la obra mucho más sustanciosamente que las de El filósofo, Leonardo y Fabricio hablan de «la dulce plática [de] la noche pasada», y el aspecto que señala Fabricio en primer lugar concierne la materia narrativa y lo que resulta de ella: le ruega a Leonardo que en futuras sesiones «no se use conmigo tanta rigurosidad como la de anoche, con tantos argumentos y preguntas como se hizo postilando mi historia [...]» (Eslava 1986: 61-62). Esta observación da paso, pues, a una formulación general de la praxis de sus tertulias; Leonardo declara, indicando otra vez la importancia primaria de la narrativa dentro de la interlocución, que «lo mejor de la conversación es esto, que el contar o el oír una historia bien dicha es poner el manjar en la boca, y el argüir después sobre ella es el mascarla y degerirla» (62). La práctica de comentar la trama y las acciones de una novela será habitual en las colecciones españolas del siglo Xvir que se valen de un marco, como lo era en las italianas desde Boccaccio, pero el procedimiento al que aluden Fabricio al hablar de las «apostillas» a su relato y Leonardo al emplear las metáforas conviviales no conlleva las más de las veces comentarios de carácter estrictamente literario, sino que genera una serie de cuestiones intelectuales. Hay algunos casos en los que se resuelven 
titubeos sobre la dinámica narrativa, sobre todo para asegurar a posteriori un cierto nivel de verosimilitud para las historias, pero mucho más a menudo los dialogantes se ponen a extraer de las novelas cortas los gérmenes de las discusiones eruditas siguientes.

Esta pauta se establece inmediatamente, aunque de forma oblicua, cuando Fabricio critica la «prolija historia» contada la noche anterior por Silvio, sobre cuyo tema principal, los consejos dados por las mujeres a los hombres, reflexiona ahora Leonardo, citando varias autoridades graves (Eslava 1986: 62-63). Y entonces el patrón se traza de manera explícita, cuando la narración de la «lastimosa historia» de un naufragio (64-73) da lugar a breves discursos eruditos y científicos sobre la amistad, el cuerpo humano y las calidades del agua (73-75) que remiten consistentemente a la trama de la novela precedente. El tema del agua conduce pues a una discusión — un poco más extendida — sobre fuentes maravillosas, la que inspira a su vez una novela sobre «una fuente, llamada del desengaño, la cual está en Siria» (77-91). Se discierne aquí una fluidez de orientación entre los contenidos eruditos y narrativos, pero este caso no desmiente la tendencia general, según la cual las novelas del volumen son el arranque y acicate de la erudición o de glosas y expansiones éticas.

En efecto, Eslava utiliza la dedicatoria del libro - la que ostenta similitudes quizá más que casuales con la dedicatoria y el prólogo de El filósofo en cuanto a las opiniones expresadas por ambos escritores sobre los peligros de la ociosidad - para hablar de sus propias lecturas doctas y su deseo de trasplantar de sus estudios «algunas preguntas de la filosofía natural y moral, insertas en apacibles historias», estrategia que describe el autor como «guisa[r] con un sainete de deleitación, para que despierte el apetito» (Eslava 1986: 53), prefiriendo dorar la píldora y no presentar los saberes en un volumen misceláneo más sobrio. A principios del segundo diálogo, Fabricio se hace eco de su autor, apoyándose ahora en la autoridad de Quintiliano y declarando que «son de mucha importancia las tales ficciones, pues con el sainete dellas se enseña mucha doctrina y filosofía natural y moral» (96). Esta filosofía, como ha demostrado Barella Vigal (1985: 546-564), es de raigambre clásica y humanista, y además de polianteas y otras compilaciones, una de las fuentes más utilizadas — pero nunca reconocidas - por Eslava es la Silva de Mexía (Barella Vigal 1985: 554-557), aunque las conversaciones no adquieren características hispanas significativas. Además, en la síntesis que pretenden los interlocutores de informaciones librescas y experiencias vividas - «de todas las cosas que he leído y visto, la que más me admira [...]» (Eslava 1986: 77) - , consecuencia natural, en cierta medida, de la forma dialogada, la obra de Eslava recuerda a misceláneas como las de Torquemada y Zapata, compartiendo con ellas también una cierta inquietud acerca de la veracidad de los elementos maravillosos que pueden surgir en las narraciones o los debates posteriores, algunos 
de los cuales enumera Mata Induráin (2004: 268-280). Después de la novelita del rey Nicíforo, Silvio confiesa que «[n]o dejo de tener alguna incredulidad» sobre la magia del rey Dárdano (Eslava 1986: 120); y el mismo personaje afirma que «[t]ambién tengo yo mi poca incredulidad, o, a lo menos, me causa grande admiración» el incendio que desoló las naves de Nicíforo (125), dudas que se resuelven por medio de auctoritates en los discursos consiguientes.

Como la sabiduría y los casos expuestos durante las conversaciones nocturnas, y a diferencia del contenido de El filósofo, las narraciones de las Noches tienen poco de español, y aunque su nivel de erudición es más alto del que percibimos en la narrativa del Para todos y en la miscelánea de Velázquez, su carácter extranjero se antoja muy marcado. Mas no por eso debemos menospreciar las modificaciones que el autor aporta a sus fuentes, estudiadas en parte por Barella Vigal (1985: 520-544). El mismo Eslava se revela a la vez consciente de sus deudas y orgulloso del artificio artístico con el que ha moldeado sus materiales novelísticos, llamando la atención sobre su práctica en la historia de «los amores de Milón de Anglante con Berta, y el nacimiento de Roldán, y sus niñerías» (Eslava 1986: 181-197). Albanio alaba a Silvio, quien «la ha contado con tanto epílogo, con tanta elegancia, discreción y gravedad en las palabras, en las sentencias, en las figuras, que son cosas que pertenecen a la Gramática, a la Dialéctica y a la Retórica, y con mucha filosofía moral» (198). Esta descripción de lo que se espera de un novelista anticipa las preceptivas fragmentarias que enunciarían próximamente Lope y Suárez de Figueroa, pero Eslava no persigue la originalidad en la elección de este tema carolingio; con su encomio, Albanio acusa jocosamente a Silvio de haber memorizado una narración que ha leído en alguna parte, crítica que acepta Silvio de buen humor. La fuente es I Reali di Francia de Barberino (Barella Vigal 1985: 532-539), pero, con su reconocimiento implícito de esta imitatio, Eslava nos invita a considerar tanto la validez como la complejidad añadida de su refundición moderna.

A la luz de estas observaciones, la adscripción genérica de las Noches de invierno permanece incierta; según la lógica estructural, lo que tenemos entre manos es una serie de novelas cortas que engendran otras series de exposiciones eruditas, pero el estatuto artístico de estas mismas ficciones se ve socavado más de una vez por la función de pretexto a la que deben servir en la presentación de saberes misceláneos. No obstante, lo que demuestran tanto el libro de Eslava como el de Velázquez, espejo el uno del otro, es un fuerte convencimiento, no sólo de la necesidad de ser uno capaz de espaciarse en los dominios de la erudición y de la ficción en prosa, sino también de la posible consustancialidad de estos dos estados. El éxito que obtienen estos autores — ya sea intelectual, ya sea novelístico- al intentar materializar esta inmanencia recíproca no es total —ni mucho menos—-, pero sus tentativas les distinguen de Pérez de Montalbán, quien produce 
una miscelánea ambiciosa sólo en apariencia. La estructura vistosa del Para todos y las pretensiones altivas del escritor encubren una desatención casi completa hacia lo que podría generar unidad o enlaces dentro de la gran variedad de contenidos eruditos y ficcionales; este hueco conceptual no es nada atípico en la tradición de la miscelánea, pero nos advierte que a fin de cuentas la academia elegante de Pérez de Montalbán no es del todo distinta de la silva caótica explorada por Mexía casi un siglo atrás.

Recibido: 17/09/2014

Aceptado: 30/10/2014

\section{OBRAS CITADAS}

AlBeRT, Mechthild (2013). «Sociabilidad y transmisión de saberes en la novela corta del Siglo de Oro». En Mechthild Albert (coord.), Sociabilidad y literatura en el Siglo de Oro. Madrid/Frankfurt am Main: Iberoamericana - Vervuert, pp. 277-299.

Alcalá Galán, Mercedes (1996). «Las misceláneas españolas del siglo XVI y su entorno cultural». Dicenda. Cuadernos de Filología Hispánica, 14, pp. 11-20.

ArCe MenÉndez, Ángeles (1975). «Notas sobre Boccaccio y Suárez de Figueroa». Filología Moderna, 55, pp. 603-612.

Barella Vigal, Julia (1985). «Las Noches de invierno de Antonio de Eslava: entre el folklore y la tradición erudita». Príncipe de Viana, 46, pp. 513-565.

BondíA, Ambrosio (2000). Cítara de Apolo y Parnaso en Aragón. José Enrique Laplana Gil (ed.). Vol. I. Huesca: Instituto de Estudios Altoaragoneses e Institución Fernando el Católico.

BradburY, Jonathan (2010). «The Miscelánea of the Spanish Golden Age: an Unstable Label». Modern Language Review, 105, pp. 1053-1071.

Cayuela, Anne (1996). Le paratexte au Siècle d'Or. Prose romanesque, livres et lecteurs en Espagne au XVIIe siècle. Ginebra: Droz.

Cerdan, Francis (1987). «Cristóbal Suárez de Figueroa y la oratoria sagrada de la España de Felipe III (En torno al alivio IV de El pasajero)». Criticón, 38, pp. 57-99.

Chevalier, Maxime (1982). Cuentos españoles de los siglos XVI y XVII. Madrid: Taurus.

Colón CALDERÓN, Isabel (2001). La novela corta en el siglo XVII. Madrid: Laberinto.

Del Piero, Raúl (1961). «La respuesta de Pérez de Montalbán a La Perinola de Quevedo». Publications of the Modern Language Association of America, 76, pp. 40-47.

Dixon, Victor (1964). «Juan Pérez de Montalbán’s Para todos». Hispanic Review, 32, pp. 36-59.

Eslava, Antonio de (1986). Noches de invierno. Julia Barella Vigal (ed.). Pamplona: Institución Príncipe de Viana.

FERNÁNDEZ, Ángel-Raimundo (1983). «Novela corta marginada del siglo XVII. (Notas sobre la Guía y avisos de forasteros y El filósofo del aldea)». En Homenaje a José Manuel Blecua: ofrecido por sus discípulos, colegas y amigos. Madrid: Gredos, pp. 175-192.

FerNÁNDEZ NieTo, Manuel (2013). «Entre costumbrismo y novela. Antonio Liñán y Verdugo y Baltasar Mateo Velázquez». Mélanges de la Casa de Velázquez, 43.2, pp. 53-67. 
GonzÁlez Ramírez, David (2007). «Lope de Vega y Castillo Solórzano: “Los mejores ingenios de España”. Consideraciones críticas sobre la transmisión, la compilación y la repercusión de las Novelas amorosas (Zaragoza, 1648)». Alazet, 19, pp. 27-54. (2011). Del taller de imprenta al texto crítico. Recepción y edición de la «Guía y avisos de forasteros» de Liñán y Verdugo. Anejos de Analecta malacitana, 79. Málaga: Universidad de Málaga.

Malpartida Tirado, Rafael (2007). «Deslindes de la miscelánea en el Renacimiento español». Epos. Revista de Filología, 23, pp. 39-60.

MatA IndurÁin, Carlos (2003). «Sobre la admiratio en las Noches de invierno de Antonio de Eslava». Zangotzarra, 7.7, pp. 91-115.

(2004). «Elementos fantásticos y maravillosos en las Noches de invierno (1609) de Antonio de Eslava». En Nicasio Salvador Miguel, Santiago López-Ríos y Esther Borrego Gutiérrez (coord.), Fantasía y literatura en la Edad Media y los Siglos de Oro. Madrid: Iberoamericana; Frankfurt am Main: Vervuert, pp. 259-282.

Mexía, Pedro (2003). Silva de varia lección. Isaías Lerner (ed.). Madrid: Castalia.

Molina, Tirso de (1994). Obras completas. Pilar Palomo y Isabel Prieto (ed.). Vol. II: Deleitar aprovechando. Madrid: Turner.

(1996). Cigarrales de Toledo. Luis Vázquez Fernández (ed.). Madrid: Castalia.

Pérez de Montalbán, Juan (1999). Obra no dramática. José Enrique Laplana Gil (ed.). Madrid: Turner.

Quevedo, Francisco de (1993). Prosa festiva completa. Celsa Carmen García-Valdés (ed.). Madrid: Cátedra.

Rallo Gruss, Asunción (1984). «Las misceláneas: conformación y desarrollo de un género renacentista». Edad de Oro, 3, pp. 159-180.

- (2013). «La novella como recurso del dialogo en la Guía y avisos de forasteros de Liñán y Verdugo». En Isabel Colón Calderón, David Caro Bragado, Clara Marías Martínez y Alberto Rodríguez de Ramos (coord.), Los viajes de Pampinea: "novella" y novela española en los Siglos de Oro. Prosa Barroca. Madrid: Sial Ediciones, pp. 201-213.

RiPoll, Begoña (1991). La novela barroca: catálogo bio-bibliográfico (1620-1700). Salamanca: Universidad de Salamanca.

Rodrigues Lobo, Francisco (1945). Côrte na aldeia e Noites de inverno. Afonso Lopes Vieira (ed.). Lisboa: Livraria Sá da Costa.

Schwartz, Lía (2000). «La retórica de la cita en las Novelas a Marcia Leonarda de Lope de Vega». Edad de Oro, 19, pp. 265-285.

SENDín Vinagre, Juan José (1998). «De novela cortesana y polianteas. Materiales enciclopédicos en Sucesos y prodigios de amor, de Juan Pérez de Montalbán». En César Hernández Alonso (coord.), Homenaje al profesor Emilio Alarcos García en el centenario de su nacimiento: 1895-1995. Valladolid: Universidad de Valladolid, pp. 193-200.

SuÁrez de FigueroA, Cristóbal (1988). El pasajero. María Isabel López Bascuñana (ed.). 2 vols. Barcelona: Promociones y Publicaciones Universitarias.

VegA, Lope de (2011). Novelas a Marcia Leonarda. Antonio Carreño (ed.). $2^{\mathrm{a}}$ ed. Madrid: Cátedra.

VelázQuez, Baltasar Mateo (1906). El filósofo del aldea. En Emilio Cotarelo y Mori (ed.), 
Novelas de Miguel Moreno, y del alférez Baltasar Mateo Velázquez. Colección selecta de antiguas novelas españolas, t. 4. Madrid: Viuda de Rico, pp. 149-335.

Yarbro-Bejarano, Yvonne (1991). The Tradition of the "Novela" in Spain from Pedro

Mexía (1540) to Lope de Vega's "Novelas a Marcia Leonarda" (1621, 1624). New

York: Garland Publishing.

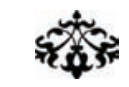

\section{LA NARRATIVA BREVE EN LA MISCELÁNEA DEL SIGLO XVII}

RESUMEN: La narrativa breve y otras formas de literatura imaginativa desempeñan un papel importante en las misceláneas españolas del siglo XVII, lo que diferencia estas obras de las misceláneas tempranas. Las funciones de estas composiciones son múltiples, y las novelas cortas presentan un notable interés: pueden ocupar un espacio ajeno a los contenidos eruditos que forman la médula de la miscelánea, o pueden interactuar con ellos de varias maneras. La novela corta evoluciona en la Península durante las primeras décadas del Seiscientos y la erudición va presentándose como atributo fundamental del novelista; la miscelánea puede ser por tanto un ámbito particularmente fecundo donde explorar esta forma literaria. En este estudio se investiga esta proposición a través de un análisis de las Noches de invierno (1609) de Eslava, El filósofo del aldea (1625) de Velázquez, y el Para todos (1632) de Pérez de Montalbán.

Palabras Claves: Misceláneas, Novela corta, Narrativa breve, Erudición, Juan Pérez de Montalbán, Baltasar Mateo Velázquez, Antonio de Eslava.

\section{Short Prose Fiction in Spanish Miscellanies of the SeVEnteenth Century}

ABSTRACT: Along with other forms of creative literature, short prose fiction plays an important role in the Spanish miscellanies of the seventeenth century, distancing these from their counterparts in the sixteenth century. The part that literary materials play in such miscellanies varies considerably, and this holds particularly true for short stories: they may function separately of the erudition which is the core of a miscellany, or they may interact with it in a number of ways. Given that the short story is an evolving medium in Golden Age Spain in which authors are encouraged to showcase their learnedness, the miscellany may be a congenial space in which to explore this literary form. I shall examine this proposition by looking at Eslava's Noches de invierno (1609), Velázquez's El filósofo del aldea (1625), and Pérez de Montalbán's Para todos (1632).

Keywords: Miscellanies, Short prose fiction, Erudition, Juan Pérez de Montalbán, Baltasar Mateo Velázquez, Antonio de Eslava. 


\section{EDAD DE ORO}

Revista de Filología Hispánica XXXIII

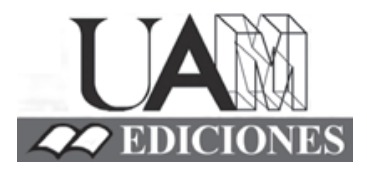




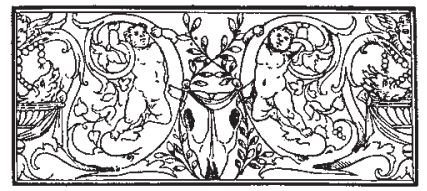

\section{Edad de Oro. Revista de Filología Hispánica}

ISSN: 0212-0429

Dirección:

Teodosio Fernández

Secretaría y edición:

José Ramón Trujillo

Coordinador del volumen XXXIII:

Rafael Bonilla Cerezo

Comité científico internacional:

Carlos Alvar (Univ. de Ginebra)

Ignacio Arellano (Univ. de Navarra)

Javier Blasco (Univ. de Valladolid)

Alberto Blecua (UAB)

Jean Canavaggio (Univ. de París X)

Laura Dolfi (Univ. de Turín)

Aurora Egido (Univ. de Zaragoza)

Víctor García de la Concha (RAE)

Luciano García Lorenzo (CSIC)

Joaquín González Cuenca (Univ. de Castilla-

La Mancha)

Agustín de La Granja (Univ. de Granada)

Begoña López Bueno (Univ. de Sevilla)

Michel Moner (Univ. de Toulouse III)

Joan Oleza (Univ. de Valencia)

Alfonso Rey (Univ. de Santiago)

Lina Rodríguez Cacho (Univ. de Salamanca)

Leonardo Romero Tobar (Univ. de Zaragoza)

Aldo Ruffinatto (Univ. de Turín)

Lía Schwartz (City University of New York)
Redacción y admisión de originales:

Teodosio Fernández

Edad de Oro

Departamento de Filología Española

Universidad Autónoma de Madrid

28049 Madrid (España)

Tfno.: +0034 914974090

correo: teodosio.fernandez@uam.es

Distribución, suscripción y venta:

Servicio de Publicaciones de la UAM

Universidad Autónoma de Madrid

28049 Madrid (España)

Intercambio de publicaciones:

Biblioteca de la Facultad de Filosofía y

Letras (UAM)

Universidad Autónoma de Madrid

28049 Madrid (España)

Han colaborado en este volumen:

Departamento de Filología Española (UAM)

Facultad de Filosofía y Letras (UAM)

Proyecto I+D FFI2013-41264-P La novela

corta del siglo XVII: estudio y edición (y II)

Edad de Oro se recoge en las siguientes bases de datos: SCOPUS, MLA Database, HLAS, Latindex, PIO-Periodical Content Index, ISOC, Dialnet, MIAR, ERIH, DICE, Sumaris CBUC, Ulrich's. Se encuentra evaluada en CIRC: A; INRECH: primer cuartil, posición 6 de 50; MIAR difusión ICDS live: 9.977; SCImago Journal \& Country Rank: H Index 2, SJR 0,101, Q4; RESH índice de impacto: 0.162; ERIH: A INT1; Carhus Plus+: B. 
Evangelina Rodríguez Cuadros (Universitat de València)

Novela cortesana, novela barroca, novela corta: de la incertidumbre al canon 9

Mita Valvassori (Universidad de Los Lagos)

El modelo narrativo del Decamerón en la Edad de Oro: una vieja historia .21

Antonio Gargano (Università degli Studi di Napoli Federico II)

«Difficile est proprie communia dicere»: el género de la novella entre

Boccaccio y Cervantes

Guillermo Carrascón (Università degli Studi di Torino)

Apuntes para un estudio de la presencia de Bandello en la

novela corta del siglo XVII

Leonardo Coppola (Università degli Studi «G. d'Annunzio» di Chieti-Pescara)

La proyección de Straparola en la novela española del Siglo de Oro desde una perspectiva editorial

Mireia Aldomà García

Didactismo, género literario y lector en Giraldi Cinzio

María Jesús Zamora (Universidad Autónoma de Madrid)

«...En tiempo menos discreto que el de agora, aunque de hombres más sabios, se

llamaban a las novelas cuentos». La novela corta y el cuento en el Siglo de Oro......109

Marcial Rubio (Università degli Studi «G. d'Annunzio» di Chieti-Pescara)

La contribución de Cervantes a la novela barroca: la ejemplaridad.

Pierre Darnis (Université Bordeaux Montaigne)

La fuerza de la sangre, La ilustre fregona $y$ Las dos doncellas: ¿tres tipos

folclóricos?

María Soledad Arredondo (Universidad Complutense de Madrid)

De La gitanilla a La sabia Flora malsabidilla. El género, el personaje

y el matrimonio

Antonella Gallo (Università degli Studi di Verona)

Fabulaciones en equívocos burlescos: la Chrónica del monstro imaginado (1615)

de Alonso de Ledesma y novela corta barroca

David González Ramírez (Universidad de Málaga)

El filósofo del aldea (1625) de Baltasar Mateo Velázquez: recepción textual

e hipótesis autorial.

JONATHAN BRADBURY (University of Exeter)

La narrativa breve en la miscelánea del siglo XVII... 
Cristina Castillo Martínez (Universidad de Jaén)

«La fuente del desengaño»: de las Noches de invierno de Eslava a la Tercera

Diana de Tejeda.

MARÍA Zerari (Université Paris-Sorbonne, CLEA)

Furor in fabula: La cruel aragonesa de Castillo Solórzano (o de la dama monstruo).. 241

Giulia Giorgi (Università degli Studi di Ferrara)

Alonso de Castillo Solórzano reescritor de sí mismo: algunas notas sobre los

Escarmientos de amor moralizados y el Lisardo enamorado .257

Angela Fabris (Alpen-Adria-Universität Klagenfurt)

El diálogo con el público y los espacios reales y de maravilla en

Casos prodigiosos y cueva encantada de Juan de Piña 267

María Rocío LePe García (IES San Sebastián, Huelva)

La traducción inglesa de Hipólito y Aminta: una adaptación

con fines comerciales 281

Andrea Bresadola (Università degli Studi di Udine)

La novela española en la Italia del siglo XVII: el caso de Il Feniso

de Francisco de Quintana.

José Teruel (Universidad Autónoma de Madrid)

El triunfo del Desengaño. Marco y desengaño postrero de la Parte segunda

del Sarao y entretenimiento honesto, de María de Zayas

Nieves Romero-Díaz (Mount Holyoke College)

Lecturas alternativas en la Novela del fin bueno en mal principio

de doña Ana Francisca Abarca de Bolea....

Shifra Armon (University of Florida)

Compromiso y distanciamiento en La Venus de Ferrara

de Mariana de Carvajal Saavedra

Mechthild Albert (Rheinische Friedrich-Wilhelms-Universität Bonn)

Las "noches": un subgénero novelístico en perspectiva comparada.... .365

Fernando Copello Jouanchin (Université du Maine, Le Mans)

El mueble en la novela corta del Siglo de Oro: algunas reflexiones

en torno a la cama

Ilaria Resta (Università del Salento):

De la novella al entremés pasando por la novela corta: reescrituras del cuento

La gara delle tre mogli del Cieco di Ferrara. 